\title{
Synthesis and Intracellular Degradation of P(3HB)/DEG Copolymers by Cupriavidus eutrophus B-10646
}

\author{
Natalia O. Zhila* \\ Institute of Biophysics SB RAS \\ 50/50 Akademgorodok, Krasnoyarsk, 660036, Russia \\ Siberian Federal University \\ 79 Svobodny, Krasnoyarsk, 660041, Russia
}

Received 28.12.2015, received in revised form 13.02.2016, accepted 01.05.2016

The study addresses synthesis and intracellular degradation of copolymers consisting of 3-hydroxybutyrate and diethylene glycol $(P(3 H B) / D E G)$ by Cupriavidus eutrophus B-10646. DEG addition to the medium at concentrations of 10-30 $\mathrm{g} / \mathrm{L}$ did not influence the yields of biomass and polymer. During intracellular degradation, content of P(3HB)/DEG copolymers and homopolymer $P(3 H B)$ decreased at 1.1-1.2 and 1.8 times respectively. Bacterial cells grown in the medium with DEG synthesized copolymer consisting of polymer fractions with low molecular weight (62-217 kDa) and high molecular weight (2810-4860 kDa), whose contents were 78.1-96.4\% and 3.6-21.9\%, respectively, depending on the culture growth phase. DEG addition to the medium caused changes in the content of fatty acids of intracellular lipids, increasing their saturation.

Keywords: $P(3 H B) / D E G$ copolymers, molecular weight, intracellular degradation, fatty acids.

DOI: $10.17516 / 1997-1389-2016-9-2-136-144$.

(C) Siberian Federal University. All rights reserved

* Corresponding author E-mail address: 1hab@ibp.ru 


\title{
Синтез и внутриклеточная деградация \\ сополимеров П(ЗГБ)/ДЭГ в культуре природного штамма \\ Cupriavidus eutrophus B-10646
}

\author{
Н.О. Жила \\ Институт биофизики СО РАН \\ Россия, 660036, Красноярск, Академгородок, 50/50 \\ Сибирский федеральный университет \\ Россия, 660041, Красноярск, пр. Свободный, 79
}

Исследован синтез и внутриклеточная деградаџия диблок-сополимеров 3-гидроксибутирата и диэтиленгликоля (П(ЗГБ)/ДЭГ) культурой Cupriavidus eutrophus B-10646. Показано, что добавление ДЭГ в среду в кониентрации 10-30 г/л не влияло на общиий выход биомассы клеток и полимера. Установлено, что сополимеры с ДЭГ в меньшей степени, чем гомополимер П(ЗГБ), подвергаются внутриклеточной деградации (их содержание снижалось соответственно в 1.1-1.2 и 1.8 раза). Синтезируемые бактериями сополимеры П(ЗГБ)/ДЭГ состояли из низкомолекулярной (62-217 кДа) и высокомолекулярной (2810-4860 кДа) фракиий, содержание которых равнялось соответственно 78.1-96.4 и 3.6-21.9 \% в зависимости от фазы роста культуры. Показано увеличение насыщенности внутриклеточных липидов Cирriavidus eutrophus B-10646, растущих в присутствии ДЭГ.

Ключевые слова: сополимеры П(ЗГБ)/ДЭГ, молекулярная масса, внутриклеточная деградация, жсирные кислоты.

\section{Введение}

Перечень известных природных полимеров гидроксипроизводных алкановых кислот (полигидроксиалканоатов - ПГА) постоянно пополняется. В зависимости от набора и соотношения мономеров, образующих ПГА, их базовые свойства значительно изменяются (Sudesh et al., 2000; Chanprateep, 2010; Chen, 2010; Volova et al., 2013). Это делает актуальным поиск штаммов и условий для синтеза новых типов полимеров этого класса.

Полиэтиленгликоли (ПЭГ), включая диэтиленгликоль (ДЭГ), являясь нейтральными водорастворимыми относительно нетоксичными полиэфирами, могут агрегироваться с фосфолипидами и белками. С 1996 г. стали появляться работы, посвященные изучению микробиологического синтеза сополимеров ПГА/ПЭГ. Установлено, что при добавлении в среду ПЭГ возможен микробиологический синтез ПГА нового типа с образованием диблока ПГА/ПЭГ, где карбоксильный конец (-СООН) цепей ПГА ковалентно связан эфирной связью с цепью ПЭГ. Это явление было названо «PEGylation» (Foster, 2007).

У большинства бактерий биосинтез и эндогенная деградация ПГА представляют собой циклический метаболический процесс. В условиях дефицита по углероду и избытка азота, необходимого для синтеза основных клеточных макромолекул (белков, нуклеиновых кислот), клеточный пул ПГА вовлекает- 
ся в метаболизм, в ходе которого полимеры разрушаются под действием внутриклеточных деполимераз и используются клетками в качестве источника энергии и углерода. Эндогенный метаболизм ПГА затрудняет получение общих высоких выходов полимеров и влияет на содержание в них отдельных мономеров. Известно, что ПГА-деполимеразы характеризуются относительной субстратной специфичностью. Так, например, ПГАдеполимеразы Hydrogenophaga pseudoflava обладают специфичностью к следующим мо-

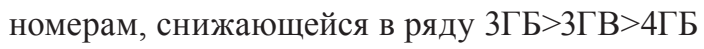
(Yoon and Choi, 1999). ПГА-деполимеразы Pseudomonas oleovorans характеризуются различной специфичностью по отношению к короткоцепочечным и среднецепочечным ПГА, а также обладают несходной структурой (Stuart et al., 1996; Foster et al., 1996). В литературе есть только одна публикация, в которой исследована внутриклеточная деградация сополимеров, содержащих ПЭГ, а именно П(3ГБ/3ГВ)/ПЭГ200, в которой показано, что деградация П(ЗГБ/3ГВ)/ПЭГ200 происходила в меньшей степени, чем П(ЗГБ) и сополимера П(ЗГБ/3ГВ) (Saha et al., 2007).

Цель данной работы - исследование биосинтеза и эндогенной деградации диблок сополимеров П(ЗГБ)/ДЭГ в культуре Cupriavidus eutrophus B-10646 и анализ влияния ДЭГ на молекулярную массу сополимера и состав жирных кислот внутриклеточных липидов.

\section{Материалы и методы}

В работе использовали штамм водородокисляющих бактерий Cupriavidus eutrophus В-10646, депонированный в ВКПМ, которые выращивали в разработанных режимах синтеза и деградации полимера, определяемых вносимыми в культуру потоками углеродного субстрата и азота (Волова и др., 1992; Volova et al., 2013, 2014). На первом этапе бактерии культивировали с лимитированным содержанием азота в среде (50 \% от потребностей культуры в элементе) в режиме максимальной аккумуляции полимера. На 72-й ч культивирования в среду добавляли хлорид аммония (1 г/л) для инициирования процесса деградации полимера. В качестве углеродного субстрата использовали фруктозу, поддерживая ее концентрацию в среде на уровне 10-13 г/л и снижая до 1-2 г/л в фазу деградации полимера. Для получения сополимеров П(ЗГБ)/ДЭГ в культуру на 24-й ч культивирования добавляли диэтиленгликоль (ДЭГ) (ОАО «Нижнекамскнефтехим», Россия) в концентрации 10 , 20 или 30 г/л. Все эксперименты проведены в трех повторностях.

Урожай биомассы клеток в ходе развития культуры бактерий регистрировали по весу сухого вещества и оптическим показателям культуры. Концентрацию фруктозы в среде анализировали резорциновым методом. Содержание и состав полимера определяли хроматографией метиловых эфиров жирных кислот с применением хромато-массспектрометра Agilent Technologies 7890A (США). Молекулярную массу и молекулярномассовое распределение полимера исследовали с использованием хроматографа для гельпроникающей хроматографии Agilent Technologies 1260 Infinity (США) относительно полистироловых стандартов (Fluka, Швейцария, Германия). Находили средневесовую $\left(\mathrm{M}_{\mathrm{B}}\right)$ и среднечисловую $\left(\mathrm{M}_{\mathrm{H}}\right)$ молекулярную мaccy, а также полидисперсность (ПД $=\mathrm{M}_{\mathrm{B}}$ / $\mathrm{M}_{\mathrm{H}}$ ). Содержание ДЭГ в сополимере определяли ${ }^{1} \mathrm{H}$ ЯМР спектроскопией растворов ПГА на ЯМР-спектрометре Bruker AVANCE III 600 (Германия) в Красноярском региональном центре коллективного пользования СО РАН.

Липиды экстрагировали из биомассы смесью хлороформ-метанол (2:1) по методу Фолча. В конечном экстракте полимер от- 
деляли от липидов осаждением при добавлении двойного объема гексана. Метанолиз жирных кислот проводили в смеси метанола и серной кислоты (50:1 по объему) в течение 2 ч при 90 $\mathrm{C}$. Анализ МЭЖК осуществляли на хромато-масс-спектрометре GC-MS 7890/5975C (Agilent Technologies, США). Идентификацию ЖК проводили по масс-спектрам и сравнением их времен удерживания с таковыми имеющихся стандартов (Serva, Германия и Sigma, США). Основные методы анализа липидов и жирных кислот подробно описаны в наших работах (Kalacheva and Volova, 2007; Kalacheva et al., 2002).

\section{Результаты и обсуждение}

Исследовано влияние различных концентраций ДЭГ (10-30 г/л) на урожай биомассы, общий выход сополимера, молекулярный вес и включение мономеров ДЭГ в полимер. Добавление ДЭГ в среду не влияло на рост бактерий и синтез полимера на первом этапе, когда в культуру подавали полную питательную среду и лимитированную концентрацию азота (50 \% от физиологической потребности). К концу первой фазы культивирования (фаза синтеза полимера) урожай биомассы и содержание полимера составляли соответственно 7.0-7.2 г/л и 79-86 \% от веса сухой биомассы (рис.). Однако к концу второй фазы культивирования, когда в клетках неизбежно проявляются процессы внутриклеточной деградации полимера, отмечены существенные различия показателей культур, растущих в присутствии в среде ДЭГ или без него (контрольная культура). В контрольной культуре к концу второй фазы концентрация клеток снизилась на $20 \%$ до 5.88 г/л, а содержание сополимера упало в 1.8 раз, до $49 \%$ от веса сухой биомассы. В отличие от контрольной культуры в культуре бактерий, растущих в присутствии ДЭГ, отмечено снижение пула полимера до
69-70 \% (от веса сухой биомассы). Урожай биомассы клеток при этом практически не изменялся, составляя 6.8-6.9 г/л.

Показано, что с увеличением концентрации ДЭГ в среде росло и содержание ДЭГ в сополимере П(ЗГБ)/ДЭГ (рис.). Так, на 72-м ч культивирования содержание ДЭГ в полимере составляло $0.17,0.23$ и 0.85 мол. \% при концентрации ДЭГ в среде 10, 20 и 30 г/л соответственно. К концу фазы внутриклеточной деградации содержание ДЭГ практически не изменилось при концентрации ДЭГ в среде 10 и 20 г/л, однако при увеличении концентрации ДЭГ до 30 г/л содержание ДЭГ в полимере снизилось до 0.35 мол. \%.

Добавление ДЭГ в культуру привело к синтезу полимера, представленного двумя фракциями (низкомолекулярной (НM), 62217 кДа и высокомолекулярной (ВМ), 28104860 кДа) (табл. 1). Распределение фракций полимера НМ и ВМ было неодинаковым в течение культивирования: на 48-й ч культивирования доля ВМ и НМ фракций составляла соответственно около 20 и 80 \%. К концу первой фазы культивирования бактерий (72 ч) доля ВМ-фракции снизилась до 4.2-5.4 \%. Гетерогенность полимера по величине молекулярной массы описана и другими авторами для бактерий Alcaligenes latus DSM 1122 и Alcaligenes eutrophus АТСС 17699 при росте на среде, содержащей ПЭГ-200 (Ashby et al., 1999). Кроме того, известно, что с увеличением концентрации ДЭГ в среде происходит снижение молекулярной массы низкомолекулярной фракции полимера, что согласуется с данными других авторов, показавших снижение Мв полимера при добавлении ДЭГ в среду (Shi et al., 1996; Ashby et al., 1997; Zanzig et al., 2003; Sanguanchaipaiwong et al., 2004). B фазе внутриклеточной деградации полимера произошло снижение доли высокомолекулярной фракции, что, возможно, связано как с 

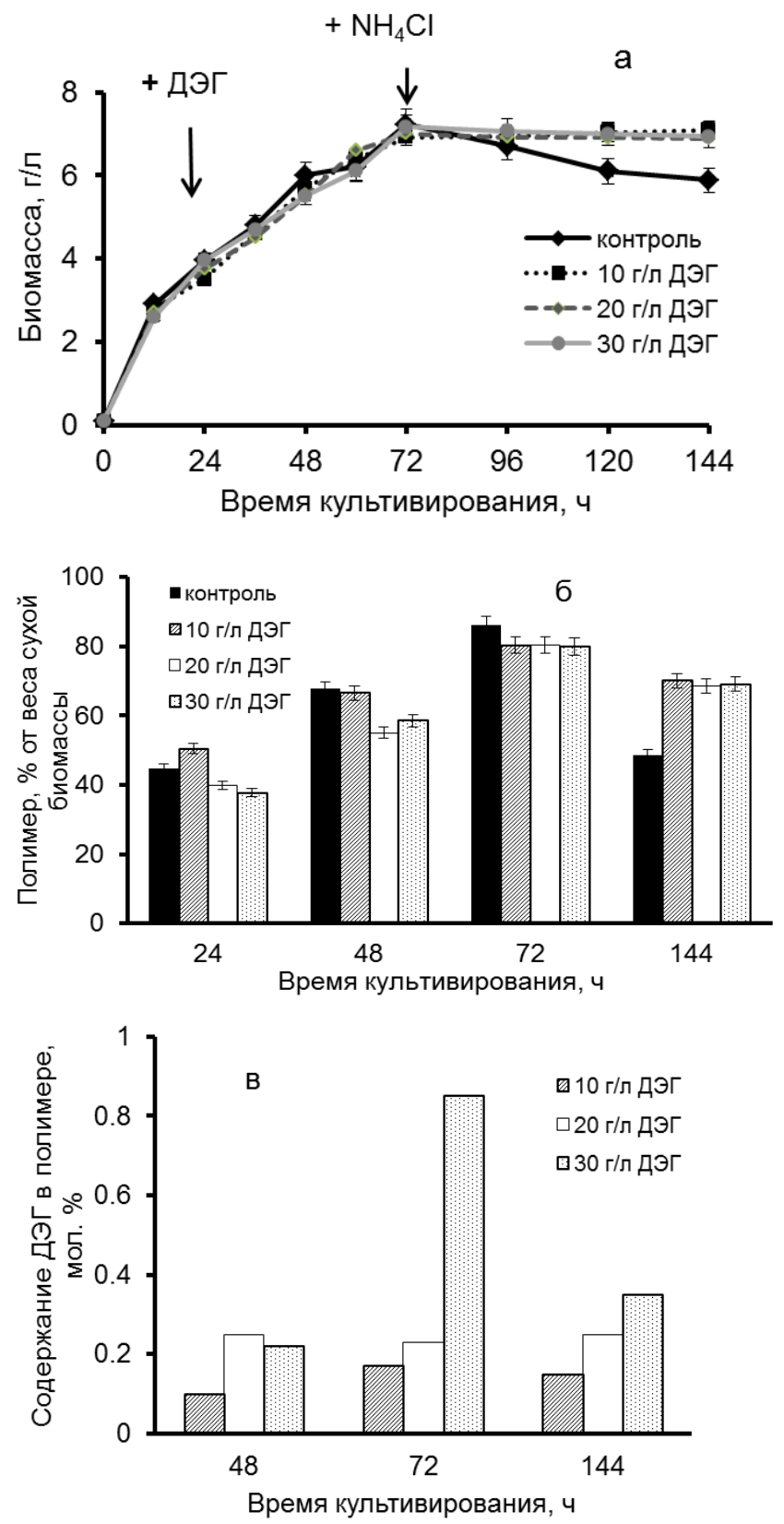

Динамика биомассы (а) бактерий Cupriavidus eutrophus B-10646, содержания полимера (б) и диэтиленгликоля (ДЭГ) в сополимере П(ЗГБ)/ДЭГ (в) в ходе накопления (до 72-го ч) и внутриклеточной деградации (после 72-го ч) полимеров при культивировании с различными концентрациями ДЭГ в среде

распадом полимера с высокой молекулярной массой, так и с синтезом низкомолекулярного полимера. Ресинтез полимера во время внутриклеточной деградации полимера был показан нами ранее (Жила и др., 2015). В кон- трольной культуре зарегистрированное снижение Мв полимера практически в два раза (от 1506 до 804 кДа) к концу 1-го этапа культивирования согласуется с ранее полученными данными других авторов для бактерий 
Таблица 1. Показатели молекулярной массы (Мв, кДа) и полидисперсности (ПД) П(ЗГБ) и сополимеров П(ЗГБ)/ДЭГ во время синтеза (до 72-го ч) и внутриклеточной деградации (144-й ч) полимера у бактерии Cupriavidus eutrophus B-10646, культивируемой при различных концентрациях диэтиленгликоля (ДЭГ) в среде

\begin{tabular}{|c|c|c|c|c|c|c|c|c|c|c|c|}
\hline \multirow{2}{*}{$\begin{array}{c}\text { Время, } \\
\text { ч }\end{array}$} & \multicolumn{3}{|c|}{10 г/л ДЭГ } & \multicolumn{3}{|c|}{20 г/л ДЭГ } & \multicolumn{3}{|c|}{30 г/л ДЭГ } & \multicolumn{2}{|c|}{ контроль } \\
\hline & Мв & ПД & Фракция, \% & Мв & ПД & Фракция, \% & Мв & ПД & Фракция, \% & Мв & ПД \\
\hline 24-й ч & 1500 & 2.58 & 100 & 1660 & 2.52 & 100 & 1630 & 2.55 & 100 & 1560 & 2.54 \\
\hline \multirow{2}{*}{ 48-й ч } & 3160 & 1.30 & 19.5 & 2900 & 1.39 & 21.9 & 2810 & 1.43 & 21.9 & \multirow{2}{*}{1200} & \multirow{2}{*}{3.55} \\
\hline & 217 & 2.92 & 80.5 & 138 & 3.33 & 78.1 & 113 & 3.54 & 78.1 & & \\
\hline \multirow{2}{*}{ 72-й ч } & 4300 & 1.14 & 4.4 & 4110 & 1.18 & 5.4 & 4860 & 1.16 & 4.2 & \multirow{2}{*}{804} & \multirow{2}{*}{3.95} \\
\hline & 138 & 2.33 & 95.6 & 89 & 2.18 & 94.6 & 67 & 2.17 & 95.8 & & \\
\hline \multirow{2}{*}{ 144-й ч } & 4080 & 1.18 & 3.9 & 4240 & 1.15 & 3.6 & 4250 & 1.17 & 3.8 & \multirow{2}{*}{936} & \multirow{2}{*}{3.32} \\
\hline & 134 & 2.23 & 96.1 & 89 & 2.24 & 96.4 & 62 & 2.15 & 96.2 & & \\
\hline
\end{tabular}

Alcaligenes eutrophus и Pseudomonas putida (Shimizu et al., 1993; Hori et al., 1994; Taidi et al., 1995; Tanadchangsaeng and Yu, 2012). Увеличение Мв полимера до 936 кДа на 2-м этапе, по всей видимости, связано с распадом фрагментов цепей П(ЗГБ) с низкой молекулярной массой.

В ходе исследования физиологического состояния культуры C. eutrophus B-10646, находящейся в режиме синтеза и внутриклеточной деградации П(ЗГБ)/ДЭГ, изучено влияние ДЭГ на состав жирных кислот липидов (ЖК), которые во многом определяют состояние и проницаемость цитоплазматической мембраны прокариот. Следует отметить, что данных о влиянии ПЭГ в процессе PEGylation и синтеза ПГА/ПЭГ на состояние клеточных мембран и на величину включения ПЭГ в ПГА/ ПЭГ в литературе не представлено. Вместе с тем в 80-90-х гг. прошлого столетия при изучении физиологической роли ПЭГ было показано, что он влияет на проницаемость мембран в результате адсорбции клеточными мембранами, связываясь с головными группами фосфолипидов, которые поддерживают текучесть мембраны (Yamazaki and Ito, 1990).

Установлено, что к концу первого этапа культивирования бактерий в среде с ДЭГ сумма циклопропановых и насыщенных ЖК (за счет 14:0, 16:0) увеличивается на фоне сни-

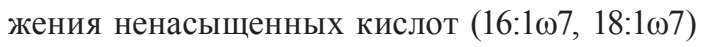
(табл. 2). В результате этого насыщенность липидов в целом возрастала от 2.65 до 3.23 3.28. Этот эффект зарегистрирован нами ранее в культурах $R$. eutropha B5786, C. eutrophus B-10646 в режиме аккумуляции ПГА по мере старения и возрастания внутриклеточного пула полимера (Kalacheva and Volova, 2007; Zhila et al., 2015). При сочетанном воздействии на культуру, синтезирующую ПГА, постороннего ингибитора (монооксида углерода как компонента синтез-газа) и лимитирования по азоту насыщенность липидов возрастала в 2.0-2.7 раза за счет снижения содержания ненасыщенных жирных кислот (в основном пальмитолеиновой, C16:1) и повышения насыщенных (пальмитиновой С16:0) и С17- и C19-циклопропановых кислот (Volova et al., 2015). Известно, что такое перераспределение в составе ЖК микроорганизмов влияет на текучесть и проницаемость мембраны, обеспечивая повышение ее «жесткости» и устойчивости к воздействию неблагоприятных факторов и снижению проницаемости для ингибирующих субстратов. В данной работе установлено, что в период внутрикле- 
Таблица 2. Состав жирных кислот внутриклеточных липидов бактерии Cupriavidus eutrophus B-10646, культивируемой при различных концентрациях диэтиленгликоля (ДЭГ) в среде ( \% от суммы жирных кислот)

\begin{tabular}{|c|c|c|c|c|c|c|c|c|}
\hline \multirow[b]{2}{*}{ Жирная кислота } & \multicolumn{4}{|c|}{ Стадия синтеза полимера (72-й ч) } & \multicolumn{4}{|c|}{ Стадия деградации полимера (144-й ч) } \\
\hline & $\begin{array}{c}10 \text { г/л } \\
\text { ДЭГ }\end{array}$ & $\begin{array}{c}20 \text { г/л } \\
\text { ДЭГ }\end{array}$ & $\begin{array}{c}30 \text { г/л } \\
\text { ДЭГ }\end{array}$ & контроль & $\begin{array}{c}10 \text { г/л } \\
\text { ДЭГ }\end{array}$ & $\begin{array}{c}20 \text { г/л } \\
\text { ДЭГ }\end{array}$ & $\begin{array}{c}30 \text { г/л } \\
\text { ДЭГ }\end{array}$ & контроль \\
\hline 14:0 & 1.08 & 0.94 & 0.85 & 0.63 & 0.67 & 0.77 & 0.62 & 1.29 \\
\hline $16: 1 \omega 7$ & 5.93 & 6.28 & 5.62 & 5.42 & 5.59 & 4.67 & 3.30 & 6.29 \\
\hline $16: 0$ & 64.99 & 66.62 & 60.99 & 59.11 & 49.62 & 52.38 & 57.35 & 57.39 \\
\hline $\mathrm{c}-17: 0^{*}$ & 8.40 & 7.10 & 12.49 & 9.69 & 16.51 & 18.56 & 13.59 & 11.14 \\
\hline 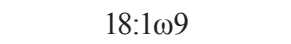 & 0.10 & 0.18 & 0.15 & 0.08 & 0.15 & 0.18 & 0.23 & 0.13 \\
\hline $18: 1 \omega 7$ & 13.86 & 13.65 & 14.55 & 18.37 & 19.27 & 16.28 & 16.60 & 16.10 \\
\hline $18: 0$ & 1.24 & 1.25 & 1.07 & 2.22 & 2.29 & 1.56 & 1.74 & 1.74 \\
\hline c-19:0* & 0.30 & 0.54 & 1.04 & 0.68 & 3.11 & 2.29 & 2.90 & 1.17 \\
\hline Другие** & 4.10 & 3.44 & 3.24 & 3.80 & 2.79 & 3.31 & 3.67 & 4.75 \\
\hline$\Sigma$ циклопропановые & 8.70 & 7.64 & 13.53 & 10.37 & 19.62 & 20.85 & 16.49 & 12.31 \\
\hline 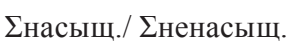 & 3.23 & 3.19 & 3.28 & 2.65 & 2.60 & 3.11 & 3.20 & 2.68 \\
\hline
\end{tabular}

* - циклопропановая жирная кислота.

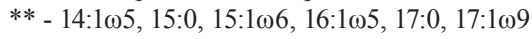

насыщ. - насыщенные жирные кислоты, включая циклопропановые жирные кислоты, ненасыщ. - ненасыщенные жирные кислоты.

точной деградации блок-сополимера П(ЗГБ)/ ДЭГ произошли изменения в составе ЖК внутриклеточных липидов бактерий главным образом за счет снижения кислот С16 ряда и увеличения ЖК С18 ряда и циклопропановых кислот, что привело к незначительному снижению насыщенности внутриклеточных липидов. Увеличение циклопропановых ЖК также отмечено и в контрольной культуре.

\section{Заключение}

Показано, что бактерии Cupriavidus eutrophus B-10646 при росте в присутствии ДЭГ синтезируют сополимеры П(ЗГБ)/ДЭГ с содержанием ДЭГ 0.1-0.85 мол. \%. В период внутриклеточной деградации наибольшие изменения, заключающиеся в снижении биомассы и в большей степени содержания полимера, отмечены в контрольной культуре. Синтезированы образцы сополимера П(ЗГБ)/ ДЭГ и установлено, что он гетерогенен по молекулярно-массовым характеристикам и представлен двумя фракциями: низкомолекулярной (62-217 кДа) и высокомолекулярной (2810-4860 кДа), доля которых менялась в зависимости от фазы роста культуры. Добавление ДЭГ в среду привело к увеличению насыщенности внутриклеточных липидов Cupriavidus eutrophus B-10646 за счет жирных кислот 14:0, 16:0 на фоне снижения содержания моноеновых кислот $(16: 1 \omega 7$,

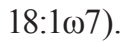

Работа выполнена за счет средств государственного задания на проведение фундаментальных исследований РАН (проект № гос. регистрации 01201351505). 


\section{Список литературы}

Волова Т.Г., Калачева Г.С., Константинова В.М., Пузырь А.П. (1992) Влияние условий роста на накопление полиоксибутирата водородными бактериями. Прикладная биохимия и микробиология, 28: 221-232 [Volova T.G., Kalacheva G.S., Konstantinova V.M., Puzyr A.P. (1992) Effect of growth conditions on olyhydroxybutyrate accumulation by hydrogen bacteria. Applied Biochemistry and Microbiology [Prikladnaya biohimiya i mikrobiologiya], 28: 221-232 (in Russian)].

Жила Н.О., Калачева Г.С., Волова Т.Г. (2015) К вопросу о внутриклеточной деградации полигидроксибутирата. Журнал Сибирского федерального университета. Биология, 8: 220-235 [Zhila N.O., Kalacheva G.S., Volova T.G. (2015) To the question about intracellular polyhydroxybutyrate degradation. Journal of Siberian Federal University. Biology [Zhurnal Sibirskogo federalnogo universiteta. Biologiya], 8: 220-235 (in Russian)].

Ashby R.D., Shi F., Gross R.A. (1997) Use of poly(ethylene glycol) to control the end group structure and molecular weight of poly(3-hydroxybutyrate) formed by Alcaligenes latus DSM 1122. Tetrahedron, 53: 15209-15223.

Ashby R.D., Shi F., Gross R.A. (1999) A tunable switch to regulate the synthesis of low and high molecular weight microbial polyesters. Biotechnol. Bioeng., 62: 106-113.

Chanprateep S. (2010) Current trends in biodegradable polyhydroxyalkanoates. J. Biosci. Bioeng., 110: 621-632.

Chen G.-Q. (2010) Industrial production of PHA. Plastics from bacteria. Natural functions and applications. Chen G.-Q., Steinbüchel A. (eds.) Berlin, Heidelberg, Springer-Verlag, p. 121-132.

Foster L.J.R., Stuart E.S., Tehrani A., Lenz R.W., Fuller R.C. (1996) Intracellular depolymerase and polyhydroxyalkanoate granule integrity in Pseudomonas oleovorans. Int. J. Biol. Macromol., 19: 177-183.

Foster L.J.R. (2007) Biosynthesis, properties and potential of natural-synthetic hybrids of polyhydroxyalkanoates and polyethylene glycols. Appl. Microbiol. Biotechnol., 75: 1241-1247.

Hori K., Soga K., Doi Y. (1994) Effects of culture conditions on molecular weights of poly(3hydroxyalkanoates) produced by Pseudomonas putida from octanoate. Biotechnol. Lett., 16: 709714 .

Kalacheva G.S., Volova T.G. (2007) Fatty acid composition of Wautersia eutropha lipids under conditions of active polyhydroxyalkanoates synthesis. Microbiology, 76: 535-540.

Kalacheva G.S., Zhila N.O., Volova T.G. (2002) Lipid and hydrocarbon compositions of collection and wild sample of the green microalga Botryococcus. Aquat. Ecol., 36: 317-330.

Saha S.P., Patra A., Paul A.K. (2007) Studies on intracellular degradation of polyhydroxyalkanoic acid-polyethylene glycol copolymer accumulated by Azotobacter chroococcum MAL-201. J. Biotechnol., 132: 325-330.

Sanguanchaipaiwong V., Gabelish C.L., Hook J., Scholz C., Foster L.J.R. (2004) Biosynthesis of natural-synthetic hybrid copolymers: polyhydroxyoctanoate-diethylene glycol. Biomacromolecules, 5: 643-649.

Shi F., Ashby R., Gross R.A. (1996) Use of poly(ethylene glycol)s to regulate poly(3hydroxybutyrate) molecular weight during Alcaligenes eutrophus cultivations. Macromolecules, 29: $7753-7758$. 
Shimizu H., Tamura S., Shioya S., Suga K.-I. (1993) Kinetic study of poly-D(-)-3-hydroxxybutyric acid (PHB) production and its molecular weight distribution control in a fed-batch culture of Alcaligenes eutrophus. J. Ferment. Bioeng., 76: 465-469.

Stuart E.S., Foster L.J.R., Lenz R.W., Füller R.C. (1996) Intracellular depolymerase functionality and location in Pseudomonas oleovorans inclusions containing polyhydroxyalkanoate. Int. J. Biol. Macromol., 19: 171-176.

Sudesh K., Abe H., Doi Y. (2000) Synthesis, structure and properties of polyhydroxyalkanoates: biological polyesters. Prog. Polym. Sci., 25: 1503-1555.

Taidi B., Mansfield D.A., Anderson A.J. (1995) Turnover of poly(3-hydroxybutyrate) (PHB) and its influence on the molecular mass of the polymer accumulated by Alcaligenes eutrophus during batch culture. FEMS Microbiol. Lett., 129: 201-206.

Tanadchangsaeng N., Yu J. (2012) Microbial synthesis of polyhydroxybutyrate from glycerol: gluconeogenesis, molecular weight and material properties of biopolyester. Biotechnol. Bioeng., 109: $2808-2818$.

Volova T.G., Kiselev E.G., Shishatskaya E.I., Zhila N.O., Boyandin A.N., Syrvacheva D.A., Vinogradova O.N., Kalacheva G.S., Vasiliev A.D., Peterson I.V. (2013) Cell growth and accumulation of polyhydroxyalkanoates from $\mathrm{CO}_{2}$ and $\mathrm{H}_{2}$ of a hydrogen-oxidizing bacterium, Cupriavidus eutrophus B-10646. Bioresour. Technol., 146: 215-222.

Volova T., Kiselev E., Vinogradova O., Nikolaeva E., Chistyakov A., Sukovatiy A., Shishatskaya E. (2014) A glucose-utilizing strain, Cupriavidus eutrophus B-10646: growth kinetics, characterization and synthesis of multicomponent PHAs. PLoS One, 9: 1-15.

Volova T.G., Zhila N.O., Shishatskaya E.I. (2015) Synthesis of poly(3-hydroxybutyrate) by the autotrophic CO-oxidizing bacterium Seliberia carboxydohydrogena Z-1062. J. Ind. Microbiol. Boitechnol., 42: 1377-1387.

Yamazaki M., Ito T. (1990) Deformation and instability in membrane structure of phospholipid vesicles caused by osmophobic association: mechanical stress model for the mechanism of poly(ethylene glycol) induced membrane fusion. Biochemistry, 29: 1309-1314.

Yoon S.C., Choi M.H. (1999) Localsequence dependence of polyhydroxyalkanoic acid degradation in Hydrogenophaga pseudoflava. J. Biol. Chem., 274: 37800-37808.

Zanzig J., Marimuthu B., Werka J., Scholz C. (2003) Investigation of the impact of poly(ethylene glycol)-modulation of poly(b-hydroxybutyrate) synthesis on cell interactions of the resulting polymers. J. Bioact. Compat. Polym., 18: 339-354.

Zhila N., Kalacheva G., Volova T. (2015) Fatty acid composition and polyhydroxyalkanoates production by Cupriavidus eutrophus B-10646 cells grown on different carbon sources. Process Biochem., 50: 69-78. 